\title{
INDISPONIBILIDADE CAUTELAR DE BENS EM AÇÕES CIVIS PÚBLICAS POR ATOS DE IMPROBIDADE ADMINISTRATIVA
}

\author{
Márcio de Almeida Farias ${ }^{1}$
}

Resumo: O objetivo do presente artigo é fazer uma análise crítica acerca do instituto jurídico da indisponibilidade de bens prevista no art. $7^{\circ}$ da Lei 8.429/92. A pesquisa é de natureza qualitativa, o método utilizado é o exploratório e a técnica de pesquisa é o levantamento bibliográfico de obras doutrinárias e jurisprudência. Conclui que a indisponibilidade de bens nas ações civis públicas de improbidade administrativa é um poderoso instrumento jurídico à disposição do Ministério Público para a defesa do patrimônio público e social, nos termos do art. 129, III, da CF/88.

Palavras-chave: Ministério Público, Patrimônio Público, Ação Civil Pública, Improbidade administrativa, Indisponibilidade cautelar de bens

\section{PRECAUTIONARY UNAVAILABILITY OF PROPERTY IN PUBLIC CIVIL ACTIONS DUE TO ADMINISTRATIVE IMPROBITY}

Abstract: The purpose of this article is to make a critical analysis of the legal institute of unavailability of assets provided for in art. 7 of Law 8.429/92. The research is qualitative in nature, the method used is exploratory and the research technique is the bibliographic survey of doctrinal works and jurisprudence. It concludes that the unavailability of assets in public civil actions of administrative improbity is a powerful legal instrument available to the Public Prosecutor's Office for the defense of public and social assets, pursuant to art. 129, III, of $\mathrm{CF} / 88$.

Keywords: Public Prosecutor's Office, Public Property, Public Civil Action, Administrative Impropriety, Precautionary Unavailability of Assets

\section{INTRODUÇÃO}

Um dos principais problemas enfrentados no Brasil é a constante prática de corrupção e de improbidade administrativa no âmbito do serviço público. Com o advento da Constituição de 1988 foram previstos dispositivos visando a solução desse problema.

Dentre esses dispositivos, podemos mencionar o art. $37, \S 4^{\circ}$, onde é previsto que os atos de improbidade administrativa importarão "a suspensão dos direitos políticos, a perda da

1 Graduado em Direito pela UFPA, Especialista em Direito Constitucional pela UNESA, Mestre em Direitos Fundamentais pela UNAMA, Promotor de Justiça do Ministério Público do Estado do Pará 
função pública, a indisponibilidade dos bens e o ressarcimento ao erário, na forma e gradação previstas em lei, sem prejuízo da ação penal cabível”.

A Lei 8.429/92 regulamentou o dispositivo acima indicado, tendo sido estabelecidos os tipos de atos de improbidade administrativa e as respectivas penalidades, dentre outras disposições.

Uma outra novidade da Constituição de 1988 foi o empoderamento do Órgão do Ministério Público, tendo o mesmo sido alçado a condição de guardião da ordem jurídica, do regime democrático e dos interesses sociais e individuais indisponíveis, nos termos do art. 127, caput. Além disso, a Constituição de 1988 incumbiu ao Ministério Público a função de defensor do patrimônio público e social, através da utilização do inquérito civil e da ação civil pública, conforme previsto no art. 129, III.

O objetivo do presente artigo é realizar uma análise crítica acerca do instituto jurídico da indisponibilidade de bens prevista no art. $7^{\circ}$ da Lei 8.429/92 (Lei de Improbidade Administrativa).

A escolha do tema justifica-se tendo em vista que a indisponibilidade de bens ser um instrumento jurídico bastante utilizado no Brasil por parte do Ministério Público visando a recomposição dos danos causados ao patrimônio público por agentes públicos e particulares, os quais tenham cometido atos de improbidade administrativa que tenham causado lesão ao erário e enriquecimento ilícito.

A metodologia utilizada no presente trabalho é a pesquisa qualitativa, sendo que as fontes de pesquisa são obras doutrinárias, a legislação nacional e a jurisprudência do Superior Tribunal de Justiça.

A abordagem terá início com a análise dos dispositivos constitucionais, acima indicados, os quais colocam o Ministério Público como guardião da moralidade e do patrimônio público, especialmente pela utilização dos instrumentos de combate à corrupção e à improbidade administrativa, como o inquérito civil e a ação civil pública.

Em seguida, faremos algumas considerações acerca do regime jurídicoadministrativo, principalmente, dos princípios da supremacia do interesse público sobre o privado e da indisponibilidade do interesse público. A violação de tais princípios, representa a prática de atos de improbidade administrativa.

Após, iremos analisar de forma mais detalhada, os dispositivos legais relativos ao instituto da indisponibilidade cautelar de bens, onde serão apresentados alguns conceitos, 
natureza jurídica e os requisitos legais, que devem ser observados pelo Ministério Público ao requer a medida, tanto de forma antecedente quanto incidental, no âmbito das ações civis pública de improbidade administrativa.

Será analisado ainda o entendimento majoritário do Superior Tribunal de Justiça (STJ), a partir de alguns julgados, acerca do referido instituto jurídico. Apresentaremos também, de forma breve, a nova sistemática da indisponibilidade de bens na futura Nova Lei de Improbidade Administrativa.

Por fim, vamos defender que o Ministério Público deverá utilizar a medida cautelar de indisponibilidade de bens, sempre que existirem indícios suficientes da prática de atos de improbidade administrativa que tenham causado lesões ao patrimônio público e social.

\section{O MINISTÉRIO PÚBLICO COMO GUARDIÃO DA MORALIDADE E DO PATRIMÔNIO PÚBLICO}

A Constituição de 1988 concedeu ao Ministério Público, cuja natureza jurídica é de função essencial à Justiça, o importante papel de guardião do regime democrático, da moralidade administrativa e do patrimônio público. É o que podemos afirmar a partir do disposto nos artigos 127, caput $^{2}$, e 129, III, da Constituição de 1988.

A respeito do Ministério Público e sua configuração constitucional, assim leciona Paulo Gustavo Gonet Branco ( 2011, p.1039) :

O Ministério Público recebeu do constituinte de 1988 tratamento singular no contexto da história do constitucionalismo brasileiro, reconhecendo-lhe uma importância de magnitude inédita na nossa história e mesmo no direito comparado. Não é possível apontar outra instituição congênere de algum sistema jurídico aparentado ao nosso a que se possa buscar socorro eficaz para a tarefa de melhor compreender a instituição como delineada aqui atualmente. O Ministério Público no Brasil, máxime após a Constituição de 1988, adquiriu feições singulares, que o estremam de outras instituições que eventualmente colham designação semelhante no direito comparado.

2

Art. 127. O Ministério Público é instituição permanente, essencial à função jurisdicional do Estado, incumbindo-lhe a defesa da ordem jurídica, do regime democrático e dos interesses sociais e individuais indisponíveis. 
Nesse sentido, a atuação do Ministério Público, especialmente em seus ramos federal e estadual, no combate à corrupção e à improbidade administrativa, é de fundamental importância em nosso Estado Democrático de Direito.

Sabemos que a corrupção e as práticas de improbidade administrativa no serviço público são grandes problemas no Brasil. Embora, a corrupção nem sempre seja praticada por agentes políticos, mas muita das vezes, ocorre até mesmo com a participação de grandes empresas, algumas até estrangeiras, que cometem toda sorte de ilegalidades para atingirem seus objetivos. Corrompem governos inteiros, autoridades de alto escalão, parlamentares, etc.

Portanto, temos no Brasil dois tipos de corrupção: uma praticada de forma comum, dentro da Administração Pública, por servidores e alguns particulares, como nas fraudes à licitação, por exemplo, onde são pagas propinas para que determinada empresa vença uma licitação e um outro tipo de corrupção, bem maior e sofisticada, cometida por uma elite poderosa, mas invisível, por meio de grandes corporações e até governos estrangeiros que interferem em algumas atividades no Brasil, dentro de uma relação de colonização. Visam, principalmente, à espoliação de nossas riquezas naturais.

Jessé Souza (2019, p. 13) explica de forma magistral como funciona essa segunda forma de corrupção:

Essa é a corrupção real. Uma corrupção legitimada e tornada invisível por uma leitura distorcida e superficial de como a sociedade e seus mecanismos de poder funcionam. (...) A construção de uma elite todo-poderosa que habitaria o Estado só existe, na realidade, para que não vejamos a elite real, que está fora do Estado, ainda que sua captura seja fundamental para seus fins. É uma ideia que nos imbeciliza, já que desloca e distorce toda a origem do poder real. Nesse esquema, se fizermos uma analogia com o narcotráfico, os políticos são os "aviõezinhos" do esquema e ficam com as sobras do saque realizado na riqueza social de todos em proveito de uma meia dúzia. Combater a corrupção de verdade seria combater a rapina, pela elite do dinheiro, da riqueza social e da capacidade de compra e de poupança de todos nós para proveito dos oligopólios e atravessadores financeiros.

Desse modo, a partir do enunciado no art. 129, III, da Constituição de 1988, cabe ao Ministério Público, não apenas uma legitimidade processual, mas, sobretudo, uma obrigação de ordem moral em combater à corrupção e à improbidade administrativa, tanto no formato comum, como explicamos acima, quanto em sua forma mais sofisticada, conforme deixa claro o autor Jessé Souza (2019, p. 13).

De acordo com o citado art. 129, III, da Constituição Federal, são funções institucionais do Ministério Público “ promover o inquérito civil e a ação civil pública, para a 
proteção do patrimônio público e social, do meio ambiente e de outros interesses difusos e coletivo."

Nesse dispositivo, vemos dois instrumentos jurídicos que poderão ser utilizados pelo Ministério Público na proteção do patrimônio público: o inquérito civil e a ação civil pública.

O inquérito civil foi previsto inicialmente pelo art. $8^{\circ}, \S 1^{\circ}$, da Lei $n^{\circ} 7.347 / 85^{3}$ ( Lei da Ação Civil Pública) e constitui-se em um procedimento investigatório exclusivo do Ministério Público, facultativo, destinado a coleta de elementos para embasar eventual ação civil pública.

Hugo Nigro Mazzili ( 2001), apresenta o seguinte conceito de inquérito civil:

É um procedimento administrativo investigatório a cargo do Ministério Público, cujo objeto consiste essencialmente na coleta de elementos de convicção que lhe sirvam de base à propositura de uma ação civil pública para a defesa de interesses transindividuais ou para a defesa do patrimônio público e social - ou seja, destina-se a colher elementos de conviçção para que, à sua vista, o Ministério Público possa identificar ou não a hipótese em que a lei exige sua iniciativa na propositura de alguma ação civil pública a seu cargo.

De acordo com a Resolução n ${ }^{\circ}$ 23/2007 do Conselho Nacional do Ministério Público em seu art. $1^{\circ}$, o inquérito civil, de natureza unilateral e facultativa, será instaurado para "apurar fato que possa autorizar a tutela dos interesses ou direitos a cargo do Ministério Público nos termos da legislação aplicável, servindo como preparação para o exercício das atribuições inerentes às suas funções institucionais."

No parágrafo único, do art. $1^{\circ}$, da Resolução no 23/2007 vemos o caráter facultativo do mesmo, pois o dispositivo afirma que "o inquérito civil não é condição de procedibilidade para o ajuizamento das ações a cargo do Ministério Público, nem para a realização das demais medidas de sua atribuição própria."

Dessa forma, o inquérito civil servirá de base à eventual ação civil pública, pois sua finalidade é a coleta de elementos de convicção. Entretanto, o mesmo não é obrigatório, como podemos verificar no art. $1^{\circ}$, paragrafo único, da Resolução ${ }^{\circ}$ 23/2007 do CNMP, pois, o Promotor de Justiça, poderá ingressar com a referida ação sem necessidade de prévio requisitar, de qualquer organismo público ou particular, certidões, informações, exames ou perícias, no prazo que assinalar, o qual não poderá ser inferior a 10 (dez) dias úteis.

Revista de Direito Administrativo e Gestão Pública | e-ISSN: 2526-0073 | Encontro Virtual | v. 7 | n. 2 | p. 01 - 20 | Jul/Dez. 2021. 
inquérito civil, caso disponha de elementos para a propositura da ação. Significa dizer, que poderá ingressar diretamente com a ação, sem precisar instaurar inquérito civil anteriormente.

O outro instrumento jurídico de proteção ao patrimônio público à disposição do Ministério Público, previsto no art. 129, III, da Constituição Federal, é justamente a ação civil pública. Esta espécie de ação judicial foi criada no Direito Brasileiro a partir da Lei no 7.347/85 e tem por finalidade a defesa dos direitos difusos e individuais indisponíveis, inclusive, o patrimônio público e social, conforme dispõe o art. $1^{0^{4}}$, inciso VIII.

A ação civil pública também poderá ser perfeitamente utilizada pelo Ministério Público para buscar a responsabilização de agentes públicos e particulares que tenham cometido atos de improbidade administrativa, nos termos do art. $37, \S 4^{\circ}$, da Constituição Federal $^{5}$ e da Lei $n^{\circ} 8.429 / 92$, que regulamentou aquele dispositivo.

Nesse sentido, temos ainda a Súmula 329 do Superior Tribunal de Justiça a qual dispõe que "o Ministério Público tem legitimidade para propor ação civil pública em defesa do patrimônio público."

Ainda dentro desse aspecto, podemos afirmar que a defesa da moralidade administrativa também é uma função ministerial, tendo em vista que a Lei no 8.625/93, a qual instituiu a Lei Orgânica Nacional do Ministério Público e criou normas gerais para a organização do Ministério Público nos Estados, dispõe em seu art. 25, inciso IV, alínea B, o seguinte:

Art. 25. Além das funções previstas nas Constituições Federal e Estadual, na Lei Orgânica e em outras leis, incumbe, ainda, ao Ministério Público:

IV - promover o inquérito civil e a ação civil pública, na forma da lei:

b) para a anulação ou declaração de nulidade de atos lesivos ao patrimônio público ou à moralidade administrativa do Estado ou de

4

Art. $1^{\circ}$ Regem-se pelas disposições desta Lei, sem prejuízo da ação popular, as ações de responsabilidade por danos morais e patrimoniais causados: 1 - ao meio-ambiente; 11 - ao consumidor;-III - a bens e direitos de valor artístico, estético, histórico, turístico e paisagístico; IV - a qualquer outro interesse difuso ou coletivo; V - por infração da ordem econômica; VI - à ordem urbanística. VII - à honra e à dignidade de grupos raciais, étnicos ou religiosos; VIII - ao patrimônio público e social.( Grifamos).

5

$\S 4^{\circ}$ Os atos de improbidade administrativa importarão a suspensão dos direitos políticos, a perda da função pública, a indisponibilidade dos bens e o ressarcimento ao erário, na forma e gradação previstas em lei, sem prejuízo da ação penal cabível. 
Município, de suas administrações indiretas ou fundacionais ou de entidades privadas de que participem;

Para Maria Sylvia Zanella Di Pietro (2002, p.79) , haverá violação ao princípio da moralidade administrativa sempre que:

(...) em matéria administrativa se verificar que o comportamento da Administração ou do administrado que com ela se relaciona juridicamente, embora em consonância com a lei, ofende a moral, os bons costumes, as regras de boa administração, os princípios de justiça e de equidade, a ideia comum de honestidade (...)

Assim, ficou evidente que o Ministério Público, na ordem jurídica brasileira, possui plena legitimidade processual para a defesa do patrimônio público contra agentes e particulares corruptos, que dilapidam tal patrimônio e que violam os princípios da Administração Pública, em especial à moralidade administrativa. Do mesmo modo, possui obrigação moral em combater a corrupção de alta envergadura cometida por uma elite de rapina, como bem explicou o autor Jessé Souza (2019, p. 13).

\section{O REGIME JURÍDICO-ADMINISTRATIVO E A IMPROBIDADE ADMINISTRATIVA}

Um conceito fundamental para compreendermos a proteção judicial do patrimônio público e da moralidade administrativa, exercida em nosso sistema, pelo Ministério Público, é o relativo ao regime jurídico-administrativo, pois de certa forma as ações civis públicas visam também a proteção desse regime.

Podemos afirmar que o regime jurídico-administrativo vem a ser um conjunto de normas jurídicas, inclusive, de princípios constitucionais, que dão à Administração Pública uma posição privilegiada em suas relações com os particulares.

Maria Sylvia Zanella Di Pietro (2002, p. 64) explica que a expressão regime jurídicoadministrativo é reservada tão somente para abranger o conjunto de traços, de conotações, que tipificam o Direito Administrativo, colocando a Administração Pública numa posição privilegiada, isto é, vertical. Afirma ainda, que basicamente, o regime jurídico-administrativo resume-se a duas palavras apenas: prerrogativas e sujeições.

A referida autora prossegue: 
Isso significa que a Administração Pública possui prerrogativas ou privilégios, desconhecidos na esfera do direito privado, tais como a autoexecutoriedade, a autotutela, o poder de expropriar, o de requisitar bens e serviços (...) Mas, ao lado das prerrogativas, existem determinadas restrições a que está sujeita a Administração, sob pena de nulidade do ato administrativo e, em alguns casos, até mesmo de responsabilização da autoridade que o editou. Dentre tais restrições, citem-se a observância da finalidade pública, bem como os princípios da moralidade administrativa e da legalidade, a obrigatoriedade de dar publicidade aos autos administrativos e, como decorrência dos mesmos, a sujeição à realização de concursos para a seleção de pessoal e de concorrência pública para a elaboração de acordos com particulares. ( Di Pietro: 2002, p. 65-66)

Celso Antônio Bandeira de Mello (2009, p. 55), ao analisar o regime jurídicoadministrativo explica que do ponto de vista jurídico esta caracterização consiste, no Direito Administrativo, "na atribuição de uma disciplina normativa peculiar que fundamentalmente, se de delineia em função da consagração de dois princípios: a) supremacia do interesse público sobre o privado; b) indisponibilidade, pela Administração, dos interesses públicos”.

A defesa do patrimônio público e social por parte do Ministério Público, como determina o art. 129, III, da Constituição de 1988, significa também a defesa desses princípios.

O princípio da supremacia do interesse público sobre o privado, significa, no dizer de Bandeira de Mello ( 2009, p. 69), que existe uma superioridade do interesse da coletividade, "firmando a prevalência dele sobre o do particular, como condição, até mesmo, da sobrevivência e asseguramento deste último. É pressuposto de uma ordem social estável, em que todos e cada um sentir-se garantidos e resguardados."

Já o princípio da indisponibilidade do interesse público por parte da Administração significa que a Administração Pública, em sentido amplo, não pode livremente dispor de seus interesses patrimoniais e bens, tendo em vista que os mesmos não pertencem ao gestor de plantão, mas sim à coletividade.

Bandeira de Mello ( 2009, p. 73-74), assim leciona acerca do princípio:

A indisponibilidade dos interesses públicos significa que, sendo interesses qualificados como próprios da coletividade - internos ao setor público - , não se encontram à livre disposição de quem quer que seja, por inapropriáveis. O próprio órgão administrativo que os representa não tem disponibilidade sobre eles, no sentido de que lhe incumbe apenas curá-los o que é também, um dever - na estrita conformidade do que predispuser a intentio legis. 
Desse modo, podemos afirmar que caso um gestor público, viole os princípios da supremacia do interesse público sobre o privado e da indisponibilidade do interesse público, que são a base do regime jurídico-administrativo, poderá ser enquadrado na Lei de Improbidade Administrativa. É justamente aí que os institutos se relacionam.

\section{INDISPONIBILIDADE CAUTELAR DE BENS NA LEI DE IMPROBIDADE ADMINISTRATIVA E NA JURISPRUDÊNCIA DO STJ}

Neste capítulo, iremos fazer uma análise crítica acerca do instituto da indisponibilidade cautelar de bens previsto no art. $7^{\circ}$ da Lei de Improbidade Administrativa (Lei $\mathrm{n}^{\mathrm{o}}$ 8.429/92), que pode ser considerado também como um eficiente instrumento a ser usado pelo Ministério Público na defesa do patrimônio público.

Antes, porém, é necessário apresentarmos alguns conceitos fundamentais para compreendermos melhor o tema. Um desses conceitos é exatamente acerca da natureza jurídica da ação civil pública. Isto porque os pedidos de indisponibilidade, via de regra, são realizados pelo Órgão ministerial no bojo dessas ações, quando as mesmas têm por fundamento a repressão de atos de improbidade administrativa.

Nesse sentido, José Henrique Mouta Araújo (2013, p. 273) explica que a ACP é utilizada como forma de controle dos atos administrativos praticados pelo Poder Público. $\mathrm{O}$ autor pondera, no entanto, que "os objetos da referida ação ultrapassam tal temática, visto que a enquadram como instrumento de tutela dos bens jurídicos previstos no art. $1^{\mathrm{o}}$ da Lei $7.347 / 85 "$.

Maria Sylvia Zanella Di Pietro (2002, p. 663), entretanto, afirma que a ação civil pública não constitui, a rigor, meio específico de controle da Administração Pública, contudo como "ela tem como legitimado passivo todo aquele que causar dano a algum interesse difuso, poderá eventualmente ser proposta contra o próprio Poder Público quando ele for o responsável pelo dano".

Di Pietro (2002, p. 667), conceitua ainda a ação civil pública como "o meio processual de que se podem valer o Ministério Público e as pessoas jurídicas indicadas em lei para a proteção de interesses difusos e gerais". 
Portanto, como ação de controle de atos administrativos, a ACP também serve, como já mencionamos anteriormente, para a defesa do patrimônio público e social por parte do Órgão ministerial. É o que está previsto no art. 129, III, da Carta Magna.

Tal dispositivo assim dispõe:

Art. 129. São funções institucionais do Ministério Público:

III - promover o inquérito civil e a ação civil pública, para a proteção do patrimônio público e social, do meio ambiente e de outros interesses difusos e coletivos;

O tema também foi pacificado pelo Superior Tribunal de Justiça, conforme vemos na Súmula no 329: “o Ministério Público tem legitimidade para propor ação civil pública em defesa do patrimônio público."

O Supremo Tribunal Federal, já enfrentou por diversas vezes o tema e confirmou a utilização da ação civil pública, por parte do Ministério Público, em defesa do patrimônio público e social.

Nesse sentido:

DIREITO PROCESSUAL CIVIL. AGRAVO INTERNO EM RECURSO EXTRAORDINÁRIO COM AGRAVO. RECURSO QUE NÃO ATACA FUNDAMENTO DA DECISÃO DO TRIBUNAL DE ORIGEM QUE INADMITIRA O RECURSO EXTRAORDINÁRIO. AÇÃO CIVIL PÚBLICA. PATRIMÔNIO PÚBLICO. LEGITIMIDADE DO MINISTÉRIO PÚBLICO. 1. A parte recorrente não atacou o fundamento da decisão do Tribunal de origem que inadmitiu o recurso extraordinário (incidência da Súmula 283/STF). Nesses casos, é inadmissível o agravo, conforme a orientação desta Corte. Precedente. 2. Esta Corte firmou entendimento acerca da legitimidade do Ministério Público para propositura de acão civil pública com o intuito de proteger o patrimônio público. 3. Inaplicável o art. $85, \S 11$, do CPC/2015, uma vez que não houve fixação de honorários advocatícios. 4. Agravo interno a que se nega provimento.(ARE 951311 AgR, Relator(a): ROBERTO BARROSO, Primeira Turma, julgado em 31/03/2017, PROCESSO ELETRÔNICO DJe086 DIVULG 25-04-2017 PUBLIC 26-04-2017). ( Grifamos).

AÇÃO CIVIL PÚBLICA. LEGITIMIDADE ATIVA. MINISTÉRIO PÚBLICO DO DISTRITO FEDERAL E TERRITÓRIOS. TERMO DE ACORDO DE REGIME ESPECIAL - TARE. POSSÍVEL LESÃO AO PATRIMÔNIO PÚBLICO. LIMITAÇÃO À ATUAÇÃO DO PARQUET. INADMISSIBILIDADE. AFRONTA AO ART. 129, III, DA CF. REPERCUSSÃO GERAL RECONHECIDA. RECURSO EXTRAORDINÁRIO PROVIDO. I - O TARE não diz respeito apenas a 
interesses individuais, mas alcança interesses metaindividuais, pois o ajuste pode, em tese, ser lesivo ao patrimônio público. II - A Constituição Federal estabeleceu, no art. 129, III, que é funcão institucional do Ministério Público, dentre outras, "promover o inquérito e a acão civil pública, para a proteção do patrimônio público e social, do meio ambiente e de outros interesses difusos e coletivos". Precedentes. III - O Parquet tem legitimidade para propor ação civil pública com o objetivo de anular Termo de Acordo de Regime Especial - TARE, em face da legitimacão ad causam que o texto constitucional lhe confere para defender o erário. IV - Não se aplica à hipótese o parágrafo único do artigo $1^{\circ}$ da Lei 7.347/1985. V - Recurso extraordinário provido para que o TJ/DF decida a questão de fundo proposta na ação civil pública conforme entender. (RE 576155, Relator(a): RICARDO LEWANDOWSKI, Tribunal Pleno, julgado em 12/08/2010, REPERCUSSÃO GERAL - MÉRITO DJe-226 DIVULG 24-11-2010 PUBLIC 25-11-2010 REPUBLICAÇÃO: DJe-020 DIVULG 3101-2011 PUBLIC 01-02-2011 EMENT VOL-02454-05 PP-01230) ( Grifamos).

Feitas essas considerações, vamos neste momento analisar, criticamente, o instituto da indisponibilidade cautelar de bens em ações civis pública de atos de improbidade administrativa, previsto no art. $7^{\circ}$ da Lei no ${ }^{\circ}$ 8.429/92.

O dispositivo assim dispõe:

Art. $7^{\circ}$ Quando o ato de improbidade causar lesão ao patrimônio público ou ensejar enriquecimento ilícito, caberá a autoridade administrativa responsável pelo inquérito representar ao Ministério Público, para a indisponibilidade dos bens do indiciado.

Parágrafo único. A indisponibilidade a que se refere o caput deste artigo recairá sobre bens que assegurem o integral ressarcimento do dano, ou sobre o acréscimo patrimonial resultante do enriquecimento ilícito.

Ao analisar o dispositivo vemos que a indisponibilidade dos bens do indiciado deve ser manejada pelo Ministério Público em casos envolvendo atos de improbidade administrativa que tenham causado lesão ao patrimônio público ou que tenham ensejado enriquecimento ilícito. Assim, podemos afirmar que a indisponibilidade de bens somente é cabível nas hipóteses previstas nos artigos $9^{\circ}$ e 10 da Lei $n^{\circ} 8.429 / 92$. Não sendo possível, portanto, em atos de improbidade violadores de princípios constitucionais, previsto no art. 11 da Lei no 8.429/92, que raramente causam prejuízos ao erário.

Indisponibilidade de bens significa o bloqueio cautelar dos bens do indiciado ou réu, incluindo contas bancárias, veículos, semoventes, imóveis, etc, no curso de um inquérito civil 
ou no curso do processo judicial de ação de improbidade, visando assegurar o ressarcimento ao erário, evitando que o agente dilapide seus bens ou repasse para terceiros.

Di Pietro (2002, p. 694) afirma que "a indisponibilidade de bens, como diz o próprio vocábulo, impede a livre disposição dos bens pelo indiciado, vedando qualquer tipo de ato jurídico que implique a transferência de seus bens a terceiros”.

Flávia Cristina Moura de Andrade e Lucas dos Santos Pavione (2014, p.59) explicam que a indisponibilidade de bens é uma medida acautelatória expressamente prevista no art. $37, \S 4^{\circ}$, da CF. "Ocorre uma espécie de congelamento do patrimônio indisponibilizado, uma vez que o requerido perde a possibilidade de circulação econômica destes bens, em quaisquer de suas modalidades", dizem.

A natureza jurídica da indisponibilidade de bens, portanto, é de medida cautelar, a ser requerida pelo Ministério Público nos termos do art. $7^{\circ}$ da Lei 8.429/92, estando presentes os requisitos das cautelares em geral.

Acerca do tema, assim lecionam Marcelo Alexandrino e Vicente Paulo (2011, p. 898):

A rigor, nem todas as consequências estabelecidas na Lei 8.429/92 para os atos de improbidade são penalidades. A indisponibilidade dos bens, por exemplo, é uma medida de natureza cautelar, que tem a finalidade, não de sancionar alguém, e sim de assegurar que a pessoa sob investigação não venha, eventualmente, a frustrar uma futura execução, por exemplo, transferindo seus bens a terceiros.

Vale ressaltar, que embora o art. $7^{\circ}$ da Lei 8.429/92, mencione que a autoridade administrativa representará ao Ministério Público a fim de que seja realizado o pedido de indisponibilidade cautelar dos bens do indiciado, o Ministério Público poderá agir de ofício, não necessitando dessa representação, requerendo diretamente ao Poder Judiciário a medida.

Nesse sentido, Di Pietro (2002, p. 694):

(...) é evidente que a medida (de indisponibilidade de bens) pode ser requerida pelo Ministério Público independentemente de representação da autoridade administrativa. Aliás, o dispositivo tem uma redação infeliz, porque, se a própria pessoa jurídica interessada tem legitimidade para propor a ação, não há razão para que ela mesma não tome a iniciativa para requerer judicialmente a decretação da indisponibilidade. Não há necessidade de requerer especificamente ao Ministério Público o exercício de uma competência que pode ser exercida pelo órgão jurídico da própria entidade a que pertence a autoridade administrativa. 
Importante questão a ser levantada é em relação à comprovação dos requisitos das medidas cautelares (o fumus boni juris e o periculum in mora), pois, a regra geral, prevista no art. 305, caput, do $\mathrm{CPC}^{6}$, é que o requerente comprove no momento da propositura da petição inicial, seja de forma preparatória ou incidental, a presença de tais requisitos.

Daniel Amorim Assumpção Neves (2010, p. 1133), ensina que o fumus boni juris, ou fumaça do bom direito, "é entendido pela doutrina majoritária como o convencimento parcial do juiz - fundado num juízo de mera probabilidade em razão da cognição sumária que faz para conceder a tutela cautelar - de que o direito material que corre perigo provavelmente exista".

Já o periculum in mora, segundo Daniel Amorim Assumpção Neves (2021, p. 1134), "representa a situação de urgência derivada do perigo que o tempo necessário para a concessão da tutela definitiva no caso concreto representa para efetividade da proteção jurisdicional". Ainda segundo o autor, sempre que o demandante comprovar que, não sendo tutelado imediatamente seu direito material, correrá sério e iminente risco de perecer.

Acerca do tema, mas agora o mesmo sendo aplicado em relação aos atos de improbidade administrativa, Flávia Cristina Moura de Andrade e Lucas dos Santos Pavione (2014, p.62), explicam que “o pedido de constrição judicial dos bens do indiciado deve basear-se em sérios indícios da prática de ato de improbidade e fundado receio de ineficácia do provimento principal, não bastando a alegação de meras suspeitas."

Entretanto, no que se refere à jurisprudência do Superior Tribunal de Justiça, podemos afirmar que o entendimento majoritário é no sentido de que o requisito do periculum in mora, ou seja, o perigo na demora, está devidamente presumido no art. 37, § $4^{\circ}$, da Constituição de 1988 e que basta ser comprovado pelo Ministério Público, o fumus bonis juris.

Desse modo, no caso concreto, deverá o representante do Órgão ministerial demonstrar, por meio de prova documental, o requisito do fumus boni juris, principalmente, que o requerido tenha praticado de forma cabal, os atos de improbidade administrativa que antecedente indicará a lide e seu fundamento, a exposição sumária do direito que se objetiva assegurar e o perigo de dano ou o risco ao resultado útil do processo. 
tenham causado enriquecimento ilícito ou lesão ao erário, nos termos dos $\operatorname{artigos} 9^{\circ}$ e 10 da Lei 8.429/92.

Nesse sentido, podemos transcrever as seguintes ementas de julgados realizados pelo

Superior Tribunal de Justiça, que sustentam a tese apresentada.

PROCESSUAL CIVIL. AGRAVO INTERNO NO RECURSO ESPECIAL. CÓDIGO DE PROCESSO CIVIL DE 2015. APLICABILIDADE. ADMINISTRATIVO. IMPROBIDADE ADMINISTRATIVA. VIOLAÇÃO AO ART. 1.022 DO CPC. DEFICIÊNCIA DE FUNDAMENTAÇÃO. INCIDÊNCIA, POR ANALOGIA, DA SÚMULA N. 284/STF. AUSÊNCIA DE PREQUESTIONAMENTO DOS ARTS. 1.228 DO CÓDIGO CIVIL, E 319, III, DO CÓDIGO DE PROCESSO CIVIL. INCIDÊNCIA DA SÚMULA N. 211/STJ. INDISPONIBILIDADE CAUTELAR DE BENS. ART. $7^{\circ}$ DA LEI N. 8.429/1992. INDÍCIOS DA PRÁTICA DE ATO ÍMPROBO. FUMUS BONI JURIS. PRESENÇA. REVISÃO. IMPOSSIBILIDADE. SÚMULA N. 07/STJ. INCIDÊNCIA. AGRAVO INTERNO PROVIDO. I - Consoante o decidido pelo Plenário desta Corte na sessão realizada em 09.03.2016, o regime recursal será determinado pela data da publicação do provimento jurisdicional impugnado. In casu, aplicase o Código de Processo Civil de 2015. II - A jurisprudência desta Corte considera que quando a arguição de ofensa ao dispositivo de lei federal é genérica, sem demonstração efetiva da contrariedade, aplica-se, por analogia, o entendimento da Súmula n. 284, do Supremo Tribunal Federal. III - A ausência de enfrentamento da questão objeto da controvérsia pelo tribunal a quo, não obstante oposição de Embargos de Declaração, impede o acesso à instância especial, porquanto não preenchido o requisito constitucional do prequestionamento, nos termos da Súmula n. 211/STJ. IV Consoante entendimento pacífico deste Tribunal Superior, o juízo pode decretar, fundamentadamente, a indisponibilidade ou bloqueio de bens do demandado, quando presentes fortes indícios de responsabilidade pela prática de ato ímprobo, prescindindo da comprovacão de dilapidacão de patrimônio, ou sua iminência. Precedentes. V - Rever o entendimento do tribunal de origem, que consignou a presenca de indícios do cometimento de improbidade administrativa, caracterizando o fumus boni juris necessário à concessão da medida constritiva, demandaria necessário revolvimento de matéria fática, o que é inviável em sede de recurso especial, à luz do óbice contido na Súmula n. 07/STJ. VI - Não apresentação de argumentos suficientes para desconstituir a decisão recorrida. VII - Agravo Interno provido, para não conhecer do Recurso Especial. (AgInt no REsp 1850269/MG, Rel. Ministro NAPOLEÃO NUNES MAIA FILHO, Rel. p/ Acórdão Ministra REGINA HELENA COSTA, PRIMEIRA TURMA, julgado em 09/03/2021, DJe 12/03/2021) ( Grifamos)

PROCESSUAL CIVIL. AGRAVO INTERNO EM RECURSO ESPECIAL. AÇÃO CIVIL PÚBLICA POR SUPOSTO ATO DE IMPROBIDADE ADMINISTRATIVA. MEDIDA CAUTELAR DE INDISPONIBILIDADE DE BENS. DEFERIMENTO, PELO TRF DA 2a. REGIÃO, DA POSTULAÇÃO DE MEDIDA DE INDISPONIBILIDADE DE BENS DOS 
RÉUS. ALEGAÇÃO, NO APELO RARO, DE QUE A CORTE DE ORIGEM NÃO IDENTIFICOU A ALTA PLAUSIBILIDADE DO DIREITO ALEGADO PELO ÓRGÃO ACUSADOR E DE QUE HOUVE EXCESSO NA CONSTRIÇÃO FRENTE AO VALOR ATRIBUÍDO À CAUSA. O TRIBUNAL DE ORIGEM, CONFORME O QUADRO EMPÍRICO ESTABILIZADO NOS AUTOS, AFIRMOU A EXISTÊNCIA DE ELEMENTOS PARA A DECRETAÇÃO DE INDISPONIBILIDADE, MOTIVO PELO QUAL NÃO HÁ FALAR EM EXCLUSÃO DO BLOQUEIO PATRIMONIAL ACAUTELATÓRIO NA ACP. VIOLAÇÃO DO ART. 7o. DA LEI 8.429/1992 INOCORRENTE. AGRAVO INTERNO DOS DEMANDADOS DESPROVIDO. 1. Cinge-se a controvérsia em perquirir se estão presentes ou não, no caso, os requisitos materiais e processuais para o deferimento da medida de indisponibilidade de bens da Ré na ACP por supostos atos de improbidade administrativa. 2. Sobre o tema, dispõe o art. 7o., parág. único da Lei 8.429/1992 que a indisponibilidade de bens recairá sobre bens que assegurem o integral ressarcimento do dano, ou sobre o acréscimo patrimonial resultante do enriquecimento ilícito. 3. Em interpretação ao referido dispositivo, esta Corte Superior firmou o entendimento de que a decretação de indisponibilidade de bens em ACP por Improbidade Administrativa dispensa a demonstracão de dilapidacão ou a tentativa de dilapidacão do patrimônio para a configuracão do periculum in mora, o qual está implícito ao comando normativo do art. 7o. da Lei 8.429/1992, bastando a demonstração do fumus boni juris que consiste em indícios de atos ímprobos (REsp. 1.366.721/BA, Rel. p/acórdão Min. OG FERNANDES, DJe 19.9.2014) (...). (AgInt no AREsp 1547826/ES, Rel. Ministro NAPOLEÃO NUNES MAIA FILHO, PRIMEIRA TURMA, julgado em 11/11/2020, DJe 17/11/2020) ( Grifamos).

Como podemos verificar, pela análise dos julgados acima, o entendimento consolidado no âmbito do Superior Tribunal de Justiça, é no sentido de que em relação à indisponibilidade de bens em ações civis públicas de improbidade administrativa, o periculum in mora é presumido pelo próprio mandamento do art. $37, \S 4^{\circ}$, da Constituição Federal, devendo o Promotor de Justiça apenas demonstrar o fumus boni juris, isto é, comprovar a existência de robustos indícios de prática de atos de improbidade administrativa.

Um outro tema relacionado à indisponibilidade de bens muito importante que também foi enfrentado pelo STJ, foi a questão da extensão dessa indisponibilidade em face dos bens do indiciado ou requerido. De acordo com o entendimento majoritário do STJ a extensão da indisponibilidade deve recair sobre a totalidade do dano causado pelo Erário.

Nesse sentido:

DIREITO PROCESSUAL CIVIL. AGRAVO INTERNO NO AGRAVO EM RESP. AGRAVO DE INSTRUMENTO INTERPOSTO NA ORIGEM 
POR PARTE ACIONADA POR IMPROBIDADE ADMINISTRATIVA, EM ORDEM A AFASTAR DECRETO DE INDISPONIBILIDADE DE BENS. RECURSO MANEJADO PELO ÓRGÃO ACUSADOR CONTRA DECISÃO MONOCRÁTICA DO MINISTRO RELATOR DESTA CORTE SUPERIOR QUE PROVEU PARCIALMENTE O AGRAVO DO IMPLICADO, EM ORDEM A LIMITAR A INDISPONIBILIDADE DE BENS QUANTO AO VALOR DO DANO PRETENDIDO PELO AUTOR DA AÇÃO, NÃO HAVENDO QUE SE FALAR EM CONSTRIÇÃO SOBRE A TOTALIDADE DO ALEGADO PREJUÍZO PARA CADA UM DOS IMPLICADOS. AFIRMAÇÃO DO ARESTO DAS ALTEROSAS DE QUE A CONSTRIÇÃO DEVE RECAIR SOBRE A TOTALIDADE DO PRETENSO DANO PARA CADA UM DOS IMPLICADOS, O QUE ESTÁ EM DISSONÂNCIA COM O ENTENDIMENTO DESTA CORTE SUPERIOR NO TEMA. AGRAVO INTERNO DO ÓRGÃO ACUSADOR DESPROVIDO. 1. Esta Corte Superior tem a diretriz de que a medida de indisponibilidade de bens na acão de improbidade deve se limitar ao total do dano apontado, sendo defeso o bloqueio alcancar o débito total em relação a cada um dos co-obrigados, ante a proibição legal do excesso na cautela (AgInt no REsp. 1.497.327/ES, Rel. p/Acórdão Min. BENEDITO GONCALVES, DJe 25.10.2018; REsp. 1.119.458/RO, Rel. Min. HAMILTON CARVALHIDO, DJe 29.4.2010). 2. A Corte de origem, ao afirmar que a constrição deve corresponder à globalidade do dano indicado, atingindo em toda essa extensão o patrimônio de cada um dos requeridos (fls. 1.078), lançou afirmação que está em adversidade com o entendimento deste Tribunal Superior no tema. 3. Portanto, ao que se dessume do aresto das Alterosas, em cotejo com as alegações recursais, o controle de legalidade exercido na espécie por esta Corte Superior importa em breve modificação ao julgado de origem, por detectar-se violação a texto de lei federal apenas quanto à afirmação do julgado recorrido de que a totalidade do dano indicado deveria causar indisponibilidade a cada um dos implicados. 4. Agravo Interno do Órgão Acusador desprovido. (AgInt no AREsp 1541350/MG, Rel. Ministro NAPOLEÃO NUNES MAIA FILHO, PRIMEIRA TURMA, julgado em 29/06/2020, DJe 01/07/2020) ( Grifamos).

Desse modo, o Órgão ministerial deverá indicar na própria petição inicial da Ação Civil Pública de Improbidade Administrativa o valor total do dano causado ao erário pelo requerido. E ao realizar o pedido de liminar deverá também requerer o bloqueio dos bens até o limite do dano.

A medida liminar de indisponibilidade dos bens concedida pelo Poder Judiciário deverá ser limitada, portanto, ao valor exato do dano. Não poderá ser superior logicamente, sob pena de nulidade.

Vale ressaltar, que em breve teremos um novo regramento legal acerca do tema, tendo em vista que a Câmara dos Deputados ter aprovado, em 16/06/2021, o Projeto de Lei no 10.887/2018, o qual pretende criar a Nova Lei de Improbidade Administrativa, revogando a 
Lei ${ }^{\circ} 8.429 / 92$. A indisponibilidade de bens é tratada no art. $16^{7}$ do referido projeto de lei. O texto aprovado foi encaminhado ao Senado Federal para ser discutido e votado.

Diante de tudo o que foi exposto neste tópico, podemos afirmar que o pedido de indisponibilidade de bens, seja do ponto de vista antecedente ou incidental, em face de agentes públicos e particulares que tenham praticado atos de improbidade administrativa, é um poderoso instrumento a disposição do Ministério Público para assegurar o ressarcimento ao erário e para garantir a defesa do patrimônio público e social, nos termos do art. 129, III, da Constituição de 1988.

\section{CONSIDERAÇÕES FINAIS}

Ante o exposto neste trabalho, podemos afirmar, em primeiro lugar, que cabe ao Ministério Público, nos termos do art. 129, III, da Constituição de 1988, em todos os seus ramos, ou seja, federal ou estadual, adotar uma postura efetiva no combate à improbidade administrativa e à corrupção. Não apenas a corrupção corriqueira que ocorre no seio da Administração Pública, mas também à corrupção de grande monta que é praticada contra os interesses do povo brasileiro, especialmente por corporações multinacionais e até governos

7

Art. 16. Na ação por improbidade administrativa poderá ser formulado, em caráter antecedente ou incidente, pedido de indisponibilidade de bens dos réus, a fim de garantir a integral recomposição do erário e a aplicação de outras sanções de natureza patrimonial. $\S 1^{\circ} \mathrm{O}$ pedido de indisponibilidade pode ser formulado independentemente da representação de que trata o art. 6o desta lei. $\S 2^{\circ} \mathrm{O}$ pedido de indisponibilidade será concedido independentemente da demonstração de perigo de dano ou de risco ao resultado útil do processo, desde que o juiz se convença da probabilidade da ocorrência dos atos descritos na petição inicial à luz dos seus respectivos elementos de instrução, após a oitiva do réu em 5 (cinco) dias. § 3o A medida pode ser decretada sem a oitiva prévia do réu, sempre que o contraditório prévio possa frustrar a efetividade da medida ou que haja outras circunstâncias que recomendem a proteção liminar. $§ 4^{\circ}$ A constrição deverá recair sobre bens que sejam suficientes para a garantia do ressarcimento ao erário dos prejuízos patrimoniais alegados e da multa civil, independentemente da época de sua aquisição. $9 \S 5^{\circ} \mathrm{O}$ valor da indisponibilidade levará em conta a estimativa de dano indicada na petição inicial, permitindo-se a sua substituição por caução idônea, fiança bancária ou seguro-garantia judicial, a requerimento do réu, bem como a sua readequação durante a instrução do processo. $\S 6^{\circ}$ A constrição patrimonial poderá incidir sobre bem de família, sempre que ausentes outros bens disponíveis em montante suficiente à garantia pretendida, competindo ao requerido a demonstração dessa suficiência. $\S 7^{\circ} \mathrm{A}$ indisponibilidade de bens de terceiro depende da instauração de incidente de desconsideração da personalidade jurídica, a ser processada na forma da lei processual. § $8^{\circ}$ Quando for o caso, o pedido incluirá a investigação, o exame e o bloqueio de bens, contas bancárias e aplicações financeiras mantidas pelo indiciado no exterior, nos termos da lei e dos tratados internacionais. § $9^{\circ}$ Aplica-se à indisponibilidade prevista neste artigo, quando requerida de forma antecedente, o previsto nos arts. 305 e 308 a 310, da Lei ${ }^{\circ} 13.105$, de 16 de março de 2015. § 10. Aplica-se à indisponibilidade de bens, regida por esta lei, no que for cabível, o regime da tutela provisória da Lei $n^{\circ} 13.105$, de 16 de março de 2015. § 11. Da decisão que defere ou indefere a medida de indisponibilidade cabe agravo de instrumento, nos termos da Lei no 13.105, de 16 de março de 2015.

Revista de Direito Administrativo e Gestão Pública | e-ISSN: 2526-0073 | Encontro Virtual | v. 7 | n. 2 | p. 01 - 20 | Jul/Dez. 2021. 
estrangeiros, que numa relação de colonialismo, espoliam as riquezas naturais do Brasil, como demonstramos ao citar no início do trabalho a obra do professor Jessé Souza.

Em segundo lugar, demonstramos que é fundamental compreendermos o funcionamento do regime jurídico-administrativo, onde a Administração Pública encontra-se numa posição de privilégio frente os particulares. A partir do momento em que os princípios da supremacia do interesse público sobre o privado e o da indisponibilidade, pela Administração, dos interesses públicos, os quais são a base do regime jurídico-administrativo, são violados, seja por agentes públicos ou particulares, estará ocorrendo a prática de atos de improbidade administrativa.

Durante este artigo, demonstramos ainda que o instituto da indisponibilidade cautelar de bens previsto no art. $7^{\circ}$ da Lei $8.429 / 92$, possui a finalidade de impedir que pessoas que tenham praticado atos de improbidade administrativa venham transferir seus bens a terceiros o que frustraria a futura recomposição dos danos causados ao patrimônio público.

Deverá o Órgão ministerial ao requerer a medida cautelar, seja em procedimento antecedente ou de forma incidental, no bojo de uma ação civil pública, demonstrar a ocorrência do fumus boni juris, ou seja, a fumaça do bom direito, no sentido de comprovar a ocorrência de fortes indícios da prática de atos de improbidade administrativa. O periculum in mora, nesses casos, é presumido, com base no art. 37, § $4^{\circ}$, da Constituição de 1988 , conforme entendimento majoritário do Superior Tribunal de Justiça.

Por fim, o limite da indisponibilidade dos bens, também de acordo com o entendimento pacífico do STJ, deverá recair sobre a totalidade do dano praticado ao erário. Não é admissível que recaia sobre valores indeterminados ou acima do dano verificado, sob pena de nulidade da medida.

Desse modo, podemos afirmar que a indisponibilidade cautelar dos bens de indiciados ou requeridos por atos de improbidade administrativa é um importante instrumento de defesa do patrimônio público e social a ser utilizado pelo Ministério Público.

\section{REFERÊNCIAS BIBLIOGRÁFICAS}


ANDRADE, Flávia Cristina Moura de; PAVIONE, Lucas dos Santos. Lei de Improbidade Administrativa. $4^{\text {a }}$ edição. Salvador: Jus Podivm: 2014.

ARAÚJO, José Henrique Mouta. Estudos de Direito Processual. Belém: Paka-Tatu, 2013.

BRASIL. Constituição da República Federativa do Brasil de 1988. Disponível em: <http://www.planalto.gov.br/ccivil_03/constituicao/constituicao.htm.> Acesso em: 16/09/2021.

BRASIL. Lei no 7.347, de 24 de julho de 1985. Disponível em: < http://www.planalto.gov.br/ccivil_03/leis/17347orig.htm > Acesso em: 17/09/2021.

BRASIL. Lei $\mathrm{n}^{\mathbf{8}}$ 8.429, de 02 de junho de 1992. Disponível em: <http://www.planalto.gov.br/ccivil_03/LEIS/L8429.htm> Acesso em: 16/09/2021.

BRASIL. Lei $\mathbf{n}^{\mathbf{0}}$ 8.625, de 12 de fevereiro de 1993. Disponível em:

< http://www.planalto.gov.br/ccivil_03/leis/18625.htm > Acesso em: 17/09/2021.

BRASIL. Projeto de Lei $\mathbf{n}^{\mathbf{0}} \mathbf{1 0 . 8 8 7 / 2 0 1 8 .}$

Disponível em: <https://www.camara.leg.br/noticias/773831-camara-aprova-proposta-querevisa-a-lei-de-improbidade-administrativa> Acesso em: 17/09/2021.

BRASIL. Resolução no 23/2007.

Disponível em: < https://www.cnmp.mp.br/portal/images/Normas/Resolucoes/Resoluo0232.pdf > . Acesso em: 17/09/2021.

BRASIL. Supremo Tribunal Federal. Acórdão no ARE 951311. Disponível em: < https://jurisprudencia.stf.jus.br/pages/search/sjur366588/false > Acesso em: 17/09/2021.

BRASIL. Supremo Tribunal Federal. Acórdão no RE 576155. Disponível em: < https://jurisprudencia.stf.jus.br/pages/search/sjur186689/false > Acesso em: 17/09/2021.

BRASIL. Superior Tribunal de Justiça. Acórdão no AgInt no REsp 1850269/MG. Disponível em: < https://scon.stj.jus.br/SCON/pesquisar.jsp> Acesso em: 16/09/2021.

BRASIL. Superior Tribunal de Justiça. Acórdão no AgInt no AREsp 1547826/ES. Disponível em: < https://scon.stj.jus.br/SCON/pesquisar.jsp> Acesso em: 16/09/2021.

BRASIL. Superior Tribunal de Justiça. Acórdão no AgInt no AREsp 1541350/MG. Disponível em: <https: https://scon.stj.jus.br/SCON/pesquisar.jsp >Acesso em: 16/09/2021.

BRASIL. Superior Tribunal de Justiça. Súmula $\mathrm{n}^{\circ}$ 329. Disponível em: < https://scon.stj.jus.br/SCON/sumstj/toc.jsplivre=329\&tipo=sumula+ou+su $\& b=S U N T \&$ thesau rus=JURIDICO\&p=true $>$ Acesso em: 16/09/2021.

DI PIETRO, Maria Sylvia Zanella. Direito Administrativo. 14a edição. São Paulo: Editora Atlas, 2002. 
MAZILLI, Hugo Nigro. Conceito de Inquérito Civil. Disponível em: <http://www.mazzilli.com.br/pages/artigos/concinqciv.pdf.>. Acesso em: 16/09/2021.

MELLO, Celso Antônio Bandeira de. Curso de Direito Administrativo. $26^{\mathrm{a}}$ edição. São Paulo: Malheiros Editores, 2008.

MENDES, Gilmar Ferreira; BRANCO, Paulo Gustavo Gonet. Curso de Direito Constitucional. $6^{\text {a }}$ edição. São Paulo: Saraiva, 2011.

NEVES, Daniel Amorim Assumpção. Manual de Direito Processual Civil. $2^{a}$ edição. São Paulo: Método, 2010.

PAULO, Vicente; ALEXANDRINO, Marcelo. Direito Administrativo Descomplicado. 19a edição. São Paulo: Método, 2011.

SOUZA, Jessé. A elite do atraso. Rio de Janeiro: Estação Brasil, 2019. 